\title{
Clean synthesis of benzylidenemalononitrile by Knoevenagel condensation of benzaldehyde and malononitrile: effect of combustion fuel on activity and selectivity of Ti-hydrotalcite and Zn-hydrotalcite catalysts
}

\author{
AMARSINH L JADHAV and GANAPATI D YADAV*D \\ Departmental of Chemical Engineering, Institute of Chemical Technology, Nathalal Parekh Marg, Matunga, \\ Mumbai, Maharashtra 400 019, India \\ E-mail: gdyadav@yahoo.com; gd.yadav@ictmumbai.edu.in
}

MS received 1 February 2019; revised 18 April 2019; accepted 10 May 2019

\begin{abstract}
Benzylidene malononitrile find applications in pharmaceutical industries, pharmacology, biotech, specialty chemicals, perfumery, and for fluorescence-based assay to determine methane and is produced by polluting routes. Hydrotalcites (HT) have been very effective as solid bases in different reactions and their properties can be changed by using different synthetic methods. In this work, the effect of additional metal in the synthesis of Al-Mg hydrotalcite was systematically studied to prepare Ti-Al-Mg (Ti modified hydrotalcite) and Zn-Al-Mg HT (Zn modified hydrotalcite) using combustion method with glycine as well as glycerol as a fuel. All synthesized catalysts were evaluated in Knoevenagel condensation of benzaldehyde with malononitrile to give benzylidene malononitrile. The catalysts were completely characterized by SEM, EDXS, $\mathrm{N}_{2}$ Adsorption, $\mathrm{CO}_{2}$-TPD and $\mathrm{NH}_{3}$-TPD and XRD techniques. Ti-Al-Mg hydrotalcite using glycine as a fuel was found to be the most active, selective and reusable catalyst. Langmuir-Hinshelwood-Hougen-Watson (LHHW) model was used to establish the reaction mechanism and kinetics. All species were weakly adsorbed leading to the second order power law model. Using mole ratio of 1:3 of benzaldehyde to malononitrile with ethyl acetate as a solvent and $2.5 \times 10^{-4} \mathrm{~g} / \mathrm{cm}^{3}$ catalyst loading, $67.1 \%$ conversion of benzaldehyde and $97.6 \%$ selectivity to benzylidene malononitrile were achieved in $4 \mathrm{~h}$ at $60^{\circ} \mathrm{C}$. The apparent activation energy was $10.01 \mathrm{kcal} / \mathrm{mol}$. The process is green.
\end{abstract}

Keywords. Combustion synthesis; hydrotalcite; Ti-Al-Mg hydrotalcite; Knoevenagel condensation; benzelidine malonontrile (or 2-benzylidenepropanedinitrile).

\section{Nomenclature}

A reactant species $\mathrm{A}$, benzaldehyde

$\mathrm{B}$ reactant species $\mathrm{B}$, malononitrile

$\mathrm{C}_{\mathrm{A}}$ concentration of $\mathrm{A}$, benzaldehyde $\left(\mathrm{mol} / \mathrm{cm}^{3}\right)$

$\mathrm{C}_{\mathrm{A} 0}$ initial concentration of $\mathrm{A}$ in bulk liquid phase $\left(\mathrm{mol} / \mathrm{cm}^{3}\right)$

$\mathrm{C}_{\mathrm{AS} 1}$ adsorption concentration of $\mathrm{A}$ on active site $\mathrm{S}_{1}$

$\mathrm{C}_{\mathrm{B}} \quad$ concentration of $\mathrm{B}\left(\mathrm{mol} / \mathrm{cm}^{3}\right)$

$\mathrm{C}_{\mathrm{B} 0}$ initial concentration of $\mathrm{B}$ in bulk liquid phase $\left(\mathrm{mol} / \mathrm{cm}^{3}\right)$

$\mathrm{C}_{\mathrm{BS} 1}$ concentration of $\mathrm{B}$ on active sites of type $\mathrm{S}_{1}$ $(\mathrm{mol} / \mathrm{g})$
$\mathrm{C}_{\mathrm{E}} \quad$ concentration of $\mathrm{E}$, product species $\left(\mathrm{mol} / \mathrm{cm}^{3}\right)$

$\mathrm{C}_{\mathrm{ES} 1}$ concentration of $\mathrm{E}$ on active sites of type $\mathrm{S}_{1}$ $(\mathrm{mol} / \mathrm{g})$

$\mathrm{C}_{\mathrm{S} 1} \quad$ concentration of vacant sites of type $\mathrm{S}_{1}(\mathrm{~mol} / \mathrm{g})$

$\mathrm{C}_{\mathrm{S} 2}$ concentration of vacant sites of type $\mathrm{S}_{2}(\mathrm{~mol} / \mathrm{g})$

$\mathrm{C}_{\mathrm{T} 1}$ total concentration of vacant sites of type $\mathrm{S}_{1}$ $(\mathrm{mol} / \mathrm{g})$

$\mathrm{C}_{\mathrm{T} 2}$ total concentration of vacant sites of type $\mathrm{S}_{2}$ $(\mathrm{mol} / \mathrm{g})$

$\mathrm{C}_{\mathrm{W}}$ concentration of $\mathrm{W}$, product species $\left(\mathrm{mol} / \mathrm{cm}^{3}\right)$

$\mathrm{C}_{\mathrm{WS} 2}$ concentration of $\mathrm{W}$ on active sites of type $\mathrm{S}_{2}$ $(\mathrm{mol} / \mathrm{g})$

E product species E, benzylidene malononitrile

\footnotetext{
*For correspondence
}

Electronic supplementary material: The online version of this article (https://doi.org/10.1007/s12039-019-1641-6) contains supplementary material, which is available to authorized users. 
$\mathrm{K}_{\mathrm{A}}$ adsorption equilibrium constant for $\mathrm{A}\left(\mathrm{cm}^{3} / \mathrm{mol}\right)$

$\mathrm{K}_{\mathrm{B}}$ adsorption equilibrium constant for $\mathrm{B}\left(\mathrm{cm}^{3} / \mathrm{mol}\right)$

$\mathrm{K}_{\mathrm{E}}$ adsorption equilibrium constant for $\mathrm{E}\left(\mathrm{cm}^{3} / \mathrm{mol}\right)$

$\mathrm{K}_{\mathrm{W}}$ adsorption equilibrium constant for $\mathrm{W}\left(\mathrm{cm}^{3} / \mathrm{mol}\right)$

M mole ratio of $\mathrm{C}_{B 0} / \mathrm{C}_{A 0}$

$-r_{A}$ rate of reaction $\left(\mathrm{mol} \mathrm{cm}{ }^{-3} \min ^{-1}\right)$

$\mathrm{W}$ product species $\mathrm{W}$, water

$\mathrm{W} \quad$ catalyst loading $\left(\mathrm{g} / \mathrm{cm}^{3}\right)$

$\mathrm{X}_{A}$ fractional conversion of $\mathrm{A}$

$\mathrm{t}$ time (min)

\section{Introduction}

Clean and green industrial processes can be developed by using solid catalysts which also lead to process intensification. Particularly in the manufacture of fine and speciality chemicals, homogeneous catalysts are still used which are polluting, and should be replaced by ecofriendly catalytic processes. In contrast with solid acids, solid bases are not so rampantly used in industrial practices despite their potential for production of bulk chemicals, fine and super-fine chemicals and pharmaceuticals and pharmacology, perfumeries and flavors. ${ }^{1-5}$ Homogeneous base catalyzed reactions constitute a large body organic transformations covering some named and common routes. Some of the well-known reactions have been studied using different solid bases; for instance, Knoevenagel ${ }^{6-8}$ and Claisen-Schmidt condensations, ${ }^{9,10}$ Michael addition, ${ }^{11}$ trans-esterification, ${ }^{12}$ aldol ${ }^{13}$ and retro-Aldol condensations, ${ }^{14}$ isomerizations, ${ }^{15}$ and alkylation. ${ }^{2,5}$ Efforts have been directed at developing new heterogeneous catalysts in many laboratories including our own to understand the nature of basicity, dual functionality and mechanisms through different sophisticated techniques. ${ }^{16,17}$ Particularly, hydrotalcites (HT) or layered double hydroxides (LDH) have been favored as solid bases to study a gamut of interesting reactions. For several reactions such as glycerol carbonate synthesis, ${ }^{8,18-22}$ and O-alkylations, ${ }^{23-25}$ supported base catalysts could be tailor-made to impart better activity and selectivity. Hydrotalcites have been modified as catalysts for making fine chemicals such as 4-O-aryloxy carbonates by alkali promoted alkaline earth metal oxides, ${ }^{25}$ dehydrozingerone by hydrotalcite $(\mathrm{HT}),{ }^{26}$ guaifenesin using HT, calcined hydrotalcite (CHT), CHT/HMS, $\mathrm{MgO}, \mathrm{Al}_{2} \mathrm{O}_{3}$ and $\mathrm{K}-\mathrm{ZrO}_{2},{ }^{27}$ vanillyl mandelic acid by silica encapsulated $\mathrm{Mg}(\mathrm{OH})_{2},{ }^{28}$ natural benzaldehyde by HT, ${ }^{21}$ 2-methoxy phenyl benzoate over alkali promoted $\mathrm{HT},{ }^{29}$ veratraldehyde by $\mathrm{La}-\mathrm{Mg}$ mixed oxide, ${ }^{30}$ and dicamba ester over $\mathrm{MgO} .{ }^{31}$ In Knoevenagel condensation, homogenous catalysts are having technical and environmental problems and previously used solid catalyst like mesoporous zeolites, amino-functionalized silica, and silicon oxynitrites are useful only in polar solvents and may be deactivated by moisture and $\mathrm{CO}_{2}$.

As the foregoing suggests HTs and modified HTs have gained considerable attraction. It is observed that modification of hydrotalcite with zinc and titanium metal enhances ion exchange capacity and acido-basic properties of catalyst to impart better catalytic properties. There are numerous methods of synthesis of HTs including co-precipitation, sol-gel, template-assisted synthesis, decomposition of nitrates, etc. These methods inherently contain a number of steps to get the final form of catalyst which are laborious, and consume more quantity of reactants. Hence, different procedures have been suggested in the literature for making metal oxide or mixed oxides like HTs. Among them, combustion synthesis has become a powerful alternative for the synthesis of materials which not only render reproducible results but also involve less number of steps. Combustion synthesis gives fine nanoscale metal oxides depending on the source of fuel and ignition temperature. Combustion synthesis ${ }^{32,33}$ produces metal oxides with high surface area, pore volume and mesoporosity and therefore it is heralded as a vital method to synthesize different catalysts. Combustion synthesis requires fewer steps to prepare catalysts; pore radius and particle size can be kept under control according to the application for which it is to be used.

Base catalysts are very commonly used in aldol condensation; however, some base catalyzed reactions like Knoevenagel condensation of benzaldehyde and malononitrile could be studied using novel solid bases. Product of this reaction benzylidene malononitrile has numerous applications in pharmaceuticals, pharmacology, biotech and perfumery industries. The current work includes synthesis of titanium and zinc modified hydrotalcite catalysts by using two different fuels in combustion synthesis, their characterization, effect of fuels on the activity of the catalyst, and application in Knoevenagel condensation of benzaldehyde and malononitrile to benzylidine malononitrile. Reaction mechanism and kinetic model were also studied. In this work both synthesis of catalysts and their applications are new.

\section{Experimental}

\subsection{Chemicals}

Aluminum nitrate nonahydrate $\left(\mathrm{Al}\left(\mathrm{NO}_{3}\right)_{3} \cdot 9 \mathrm{H}_{2} \mathrm{O}\right)$, magnesium nitrate hexahydrate $\left(\mathrm{Mg}\left(\mathrm{NO}_{3}\right)_{2} \cdot 6 \mathrm{H}_{2} \mathrm{O}\right)$, glycerol, zinc 
Table 1. Preparation of different catalysts.

\begin{tabular}{|c|c|c|c|c|c|c|}
\hline Catalyst & Catalyst-Fuel & $\begin{array}{l}\mathrm{Al}\left(\mathrm{NO}_{3}\right)_{3} \\
9 \mathrm{H}_{2} \mathrm{O} \mathrm{mol}\end{array}$ & $\begin{array}{l}\mathrm{Mg}\left(\mathrm{NO}_{3}\right)_{2} \cdot \\
6 \mathrm{H}_{2} \mathrm{O} \mathrm{mol}\end{array}$ & $\begin{array}{l}\text { Titanium } \\
\text { isopropoxide } \\
\text { mol }\end{array}$ & $\begin{array}{c}\text { Zinc } \\
\text { nitrate } \\
\text { mol }\end{array}$ & Fuel mol \\
\hline Hydrotalcite-Glycerol & HT & 0.016 & 0.048 & - & - & 0.051 \\
\hline $\mathrm{TiMg}_{4} \mathrm{Al}_{2} \mathrm{O}_{9}$ Glycine & Ti-HT-Glycine & 0.016 & 0.032 & 0.008 & - & 0.054 \\
\hline $\mathrm{ZnMg}_{4} \mathrm{Al}_{2} \mathrm{O}_{8}$ Glycine & Zn-HT-Glycine & 0.016 & 0.032 & - & 0.008 & 0.054 \\
\hline $\mathrm{TiMg}_{4} \mathrm{Al}_{2} \mathrm{O}_{9}$ Glycerol & Ti-HT-Glycerol & 0.016 & 0.032 & 0.008 & & 0.042 \\
\hline $\mathrm{ZnMg}_{4} \mathrm{Al}_{2} \mathrm{O}_{8}$ Glycerol & Zn-HT-Glycerol & 0.016 & 0.032 & - & 0.008 & 0.042 \\
\hline
\end{tabular}

Slurry thickening Temp. $80{ }^{\circ} \mathrm{C}$, Combustion Temp. $500{ }^{\circ} \mathrm{C}$, Calcination Temp. $650{ }^{\circ} \mathrm{C}$.

nitrate, glycine, titanium tetraisopropoxide, nitric acid (70\%), methanol, benzaldehyde and malononitrile were purchased from S.D. Fine Chemicals, Mumbai, India. All other analytical reagent grade chemicals were used without any further purification in the synthesis of catalysts.

\subsection{Catalyst preparation}

2.2a Hydrotalcite: The synthesis of hydrotalcite $(\mathrm{Mg}-$ Al-O mixed oxide) was achieved by dissolution of $\mathrm{Al}\left(\mathrm{NO}_{3}\right)_{3}$. $9 \mathrm{H}_{2} \mathrm{O}(0.016 \mathrm{~mol})$ and $\mathrm{Mg}\left(\mathrm{NO}_{3}\right)_{2} \cdot 6 \mathrm{H}_{2} \mathrm{O}(0.048 \mathrm{~mol})$ in glycerol/glycine $(0.051 \mathrm{~mol})$ as fuel using some water to make a paste. $\mathrm{Al}$ and $\mathrm{Mg}$ nitrate ratio was kept at 1:3. Surplus water was removed by heating the mixture at $80^{\circ} \mathrm{C}$ in the crucible. It led to a thick paste which was then heated in a muffle furnace at $500{ }^{\circ} \mathrm{C}$ which resulted in spontaneous combustion. At $500{ }^{\circ} \mathrm{C}$ combustion takes place due to the fuel forming gaseous products which lead to the generation of a porous network of the solid material. Since glycine was used the combustion products were $\mathrm{CO}_{2}, \mathrm{H}_{2} \mathrm{O}$ and nitrogen. Oxides of the metals were formed. ${ }^{34}$

The solid material after spontaneous combustion was then calcined at $650{ }^{\circ} \mathrm{C}$ for $3 \mathrm{~h}$ in a furnace. ${ }^{21,22} \mathrm{In}$ combustion synthesis method metal nitrates act as oxidizers whereas carbonaceous fuels like glycine and glycerol as reducing agents. The fuel also acts as a complexant for metal cations increasing their solubility and preventing crystallization of dehydrated metal nitrate. These are sources of carbon and hydrogen for combustion. Different amounts of the fuel also affect morphology and acido-basic properties of catalyst because of the evolution of different quantities of gases. Sufficient amount of fuel is thus required for complete combustion as given by the stoichiometry below. ${ }^{34,35}$

Reaction stoichiometry for best Ti-HT-Glycine:

$$
\begin{gathered}
4 \mathrm{Mg}\left(\mathrm{NO}_{3}\right)_{2}+\mathrm{TiO}\left(\mathrm{NO}_{3}\right)+2 \mathrm{Al}\left(\mathrm{NO}_{3}\right)_{3} \\
+6.72 \mathrm{C}_{2} \mathrm{H}_{5} \mathrm{NO} \rightarrow 10.86 \mathrm{~N}_{2}+6.9 \mathrm{CO}_{2} \\
+16.81 \mathrm{H}_{2} \mathrm{O}+\mathrm{TiMg} \mathrm{Al}_{2} \mathrm{O}_{9}
\end{gathered}
$$

Reaction stoichiometry for Ti-HT-Glycerol

$$
\begin{gathered}
2 \mathrm{Al}\left(\mathrm{NO}_{3}\right)_{3}+4 \mathrm{Mg}\left(\mathrm{NO}_{3}\right)_{2}+5.28 \mathrm{C}_{3} \mathrm{H}_{8} \mathrm{O}_{3}+\mathrm{Ti}\left(\mathrm{NO}_{3}\right)_{4} \\
\rightarrow \mathrm{TiMg}_{4} \mathrm{Al}_{2} \mathrm{O}_{3}+15.85 \mathrm{CO}_{2}+21.14 \mathrm{H}_{2} \mathrm{O}+9 \mathrm{~N}_{2}
\end{gathered}
$$

Table 1 gives the preparation of $\mathrm{Zn}$ and Ti loaded catalysts vis-à-vis hydrotalcite. The composition of the materials is given there.

\subsection{Reaction setup and procedure}

Knoevenagel condensation reaction was carried out in a standard cylindrical glass reactor of $100 \mathrm{~mL}$ volume with 4-baffles and overhead stirrer. The stirrer was a $45^{\circ}$ pitched blade turbine impeller connected to a speed regulator. The reactor was kept in a thermostatic oil bath to maintain the desired temperature. In a typical run, 0.0094 mol benzaldehyde (limiting reactant) and $0.028 \mathrm{~mol}$ malononitrile were introduced in the reactor to make total reaction volume of $20 \mathrm{~mL}$ with ethyl acetate as solvent. The reaction mixture was heated to $60{ }^{\circ} \mathrm{C}$ at $1000 \mathrm{rpm}$. The catalyst loading was $0.0025 \mathrm{~g} / \mathrm{cm}^{3}$. The sample was filtered using a centrifuge and then it was diluted with ethyl acetate to make $20 \mathrm{~mL}$ sample and analyzed by GC (Chemito 1000) using BP-50 mid-polar column (25 mm x 30 $\mathrm{m})$. Nitrogen was used as a carrier gas at a flow rate of 1.0 $\mathrm{mL} / \mathrm{min}$.

\subsection{Catalyst characterization}

All five catalysts were characterized by EDXS (JOEL JSM 6308LA Analytical scanning Microscope) using 10 kV voltage at a counting rate of $519 \mathrm{cps}$ and energy range of 0-20 Kev and SEM images were procured. The textural analysis of catalysts was performed by nitrogen adsorption using a Micromeritics ASAP 2020 instrument. 10\% v/v CO in $\mathrm{He}$ and $10 \% \mathrm{v} / \mathrm{v} \mathrm{NH}_{3}$ in $\mathrm{He}$ TPD was used to determine basic and acidic site densities of catalysts, respectively. Bruker AXS diffractometer $\mathrm{D} 8$ advance $\mathrm{Cu}-\mathrm{K} \alpha$ radiation $(\lambda=1.540562)$ was used to acquire powder XRD patterns of catalysts.

\section{Results and Discussion}

\subsection{Catalyst characterization}

3.1a SEM and EDXS: SEM images of all five catalysts are shown in Figure 1. The average particle size is in the range of $50-100 \mu \mathrm{m}$. These catalytic samples show 

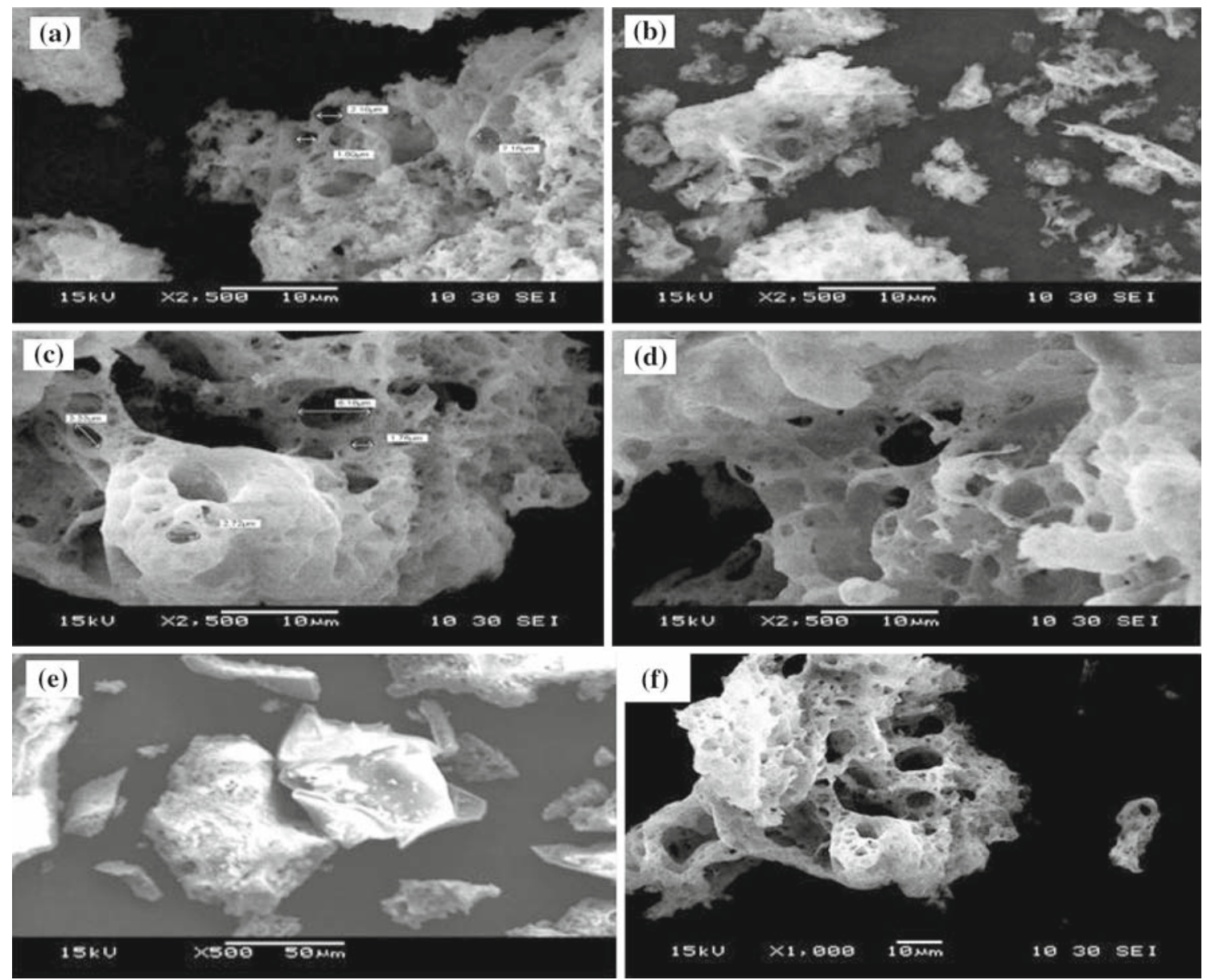

Figure 1. SEM images of different catalysts. (a) Zn-HT-Glycine, (b) Zn-HT-Glycerol, (c) Ti-HT-Glycine, (d) Ti-HT-Glycerol (all x2500), (e) HT-Glycerol (x500) (f) Reused Ti-HT-Glycine.

Table 2. Composition of different catalysts using EDXS.

\begin{tabular}{|c|c|c|c|c|c|c|c|c|c|c|}
\hline \multirow[t]{3}{*}{ Element } & \multicolumn{10}{|c|}{ Catalyst-Fuel } \\
\hline & \multicolumn{2}{|c|}{ Ti-HT-Glycine } & \multicolumn{2}{|c|}{ Ti-HT-Glycerol } & \multicolumn{2}{|c|}{ Zn-HT-Glycine } & \multicolumn{2}{|c|}{ Zn-HT-Glycerol } & \multicolumn{2}{|c|}{ HT-Glycerol } \\
\hline & Mass wt. $\%$ & $\mathrm{Mol} \%$ & Mass wt. $\%$ & Mol \% & Mass wt. $\%$ & Mol \% & Mass wt. \% & Mol \% & Mass wt. \% & Mol \% \\
\hline $\mathrm{O}$ & 42.69 & - & 42.66 & - & 29.66 & - & 31.77 & - & - & - \\
\hline $\mathrm{Mg}$ & 18.54 & 50.06 & 18.55 & 50.06 & 19.24 & 49.60 & 20.28 & 52.10 & 76.44 & 75 \\
\hline $\mathrm{Al}$ & 20.76 & 25.26 & 20.79 & 25.26 & 6.97 & 8.09 & 10.37 & 12.00 & 23.56 & 25 \\
\hline $\mathrm{Zn}$ & - & - & - & - & 44.14 & 42.31 & 37.37 & 35.90 & - & - \\
\hline $\mathrm{Ti}$ & 18.1 & 24.68 & 18.0 & 24.68 & - & - & - & - & - & - \\
\hline Total & 100 & 100 & 100 & 100 & 100 & 100 & 100 & 100 & 100 & 100 \\
\hline
\end{tabular}

irregular morphology and non-agglomerated particles, but they are fairly uniform in size which is generally seen for materials synthesized by combustion method. Reused catalyst after the second cycle has retained its highly porous nature. EDXS was used to determine the complete composition of titanium, zinc, aluminum and magnesium. The ratio of composition of aluminum and magnesium was maintained constant as follows: $(\mathrm{Al} / \mathrm{Mg}$ ratio of $1: 3)$ in HT-Glycerol, $(\mathrm{Al} / \mathrm{Mg}$ ratio of $1: 2)$ in
Ti-HT with glycine and glycerol as fuels, (A1/Mg of 1:4) in Zn-HT with glycine and glycerol as fuels. The composition of different catalysts is given in Table 2 .

\section{1b Textural properties by nitrogen adsorption} method: Nitrogen adsorption-desorption isotherm was found to be of type IV or V. This isotherm shows a small hill at high relative pressure, which is characteristic of mesoporous materials. Surface areas given 
Table 3. Performance of different catalysts for Knoevenagel condensation of benzaldehyde and malononitrile with regard to textural properties, acidity and basicity.

\begin{tabular}{|c|c|c|c|c|c|c|c|}
\hline Catalyst-fuel & $\begin{array}{l}\text { Surface } \\
\text { area } \\
\left(\mathrm{m}^{2} / \mathrm{g}\right)\end{array}$ & $\begin{array}{l}\text { Pore } \\
\text { volume } \\
\left(\mathrm{cm}^{3} / \mathrm{g}\right)\end{array}$ & $\begin{array}{l}\text { Acidity } \\
(\mathrm{mmol} / \mathrm{g})\end{array}$ & $\begin{array}{l}\text { Basicity } \\
(\mathrm{mmol} / \mathrm{g})\end{array}$ & $\begin{array}{l}\text { Conversion of } \\
\text { benzaldehyde } \\
\%\end{array}$ & Selectivity \% & Yield \% \\
\hline Ti-HT-Glycine & 226.2 & 0.252 & 0.0145 & 1.244 & 66.9 & 97.6 & 65.0 \\
\hline Zn-HT-Glycine & 132.4 & 0.339 & 0.0135 & 0.540 & 61.1 & 95.2 & 58.1 \\
\hline Zn-HT-Glycerol & 148.6 & 0.446 & 0.0145 & 1.770 & 58.0 & 93.1 & 54.0 \\
\hline Ti-HT-Glycerol & 45.6 & 0.227 & 0.719 & 1.085 & 57.0 & 92.0 & 52.4 \\
\hline HT-Glycerol & 127.0 & 0.418 & 0.6603 & 1.371 & 58.0 & 91.5 & 53.0 \\
\hline
\end{tabular}

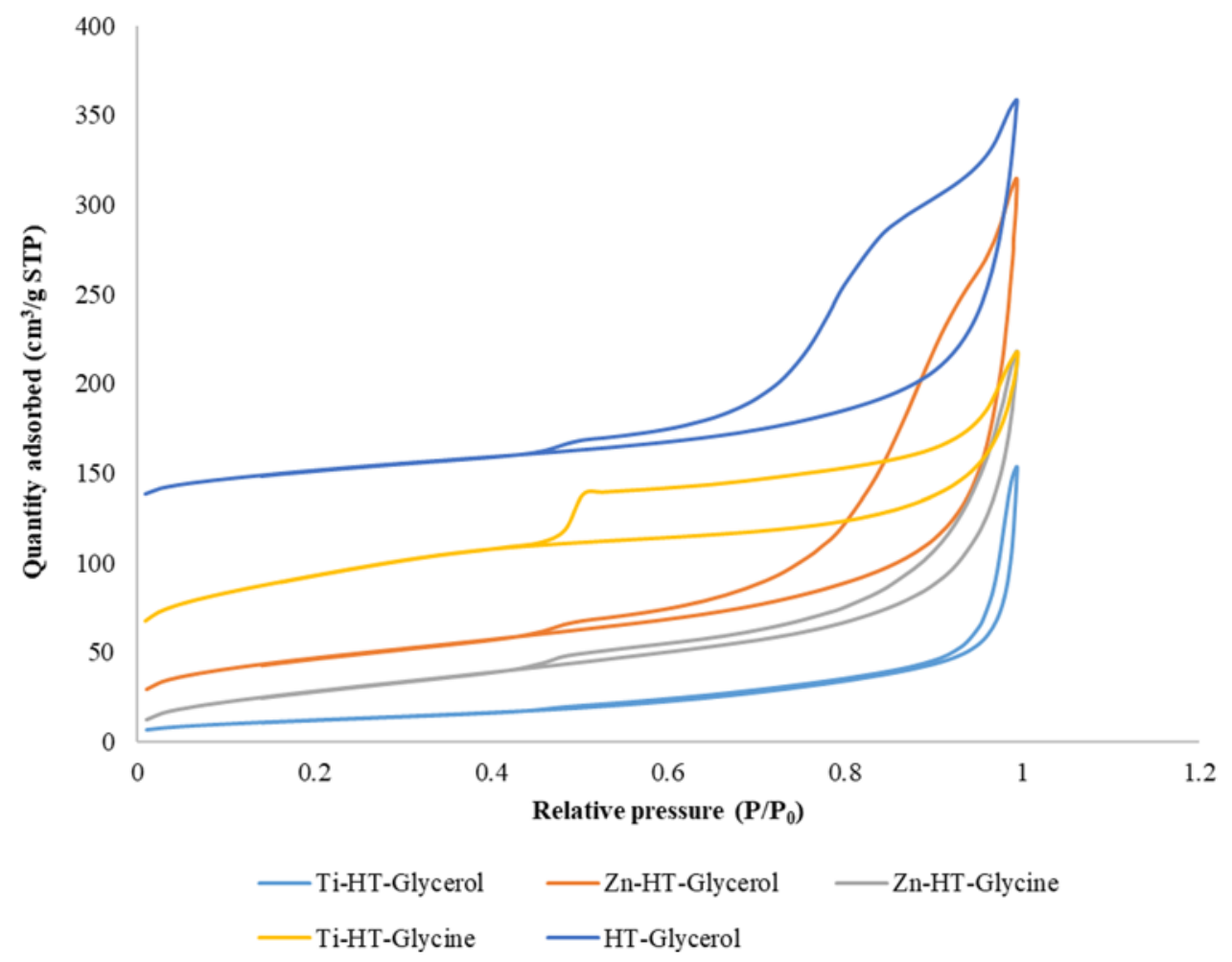

Figure 2. Nitrogen BET adsorption-desorption profiles for different catalysts.

by nitrogen adsorption are $226.2,132.4,148.6,45.6$ and $127.0 \mathrm{~m}^{2} / \mathrm{g}$ for Ti-HT-Glycine, Zn-HT-Glycine, Zn-HT-Glycerol, Ti-HT-Glycerol, and HT-Glycerol, respectively (Table 3 ). Figure 2 also justifies that surface area for catalyst Ti-HT- Glycine is the largest among all. Pore size distribution shows that a major part of the surface area is contributed by pores ranging from 5 to 20 $\mathrm{nm}$. It suggests the mesoporous character of catalysts. The complete explosive decomposition of the organic compound takes place in the case of glycine at a lower temperature as compared to glycerol. The stoichiometry also shows different quantities of gases are formed which lead to the different porous structure which is due to oxide formation. It enhances surface area and activity of the catalyst. 3.1c Acidity and basicity by TPD: In the $\mathrm{CO}_{2} \mathrm{TPD}$, intermediate and strong basic sites are shown at some specific temperature by well-defined peaks (Figure 3) due to surface basic oxygen atoms for all catalysts used. Zn-HT-Glycine and Ti-HT-Glycine show moderate to strong basic sites from $200-400{ }^{\circ} \mathrm{C}$. With $\mathrm{NH}_{3}$-TPD some broad peaks are seen below $200{ }^{\circ} \mathrm{C}$ for all catalysts which indicate that some sites are of intermediate and weak acidic nature due to $\mathrm{H}^{+}$ ions linked with surface hydroxyl groups (Figure 4). Table 2 also includes both acidic and basic site concentrations for all catalysts which are related to the surface area. Ti-HT-Glycine catalyst shows even distribution of sites having the maximum surface area which are reflected in its activity. Results show that 


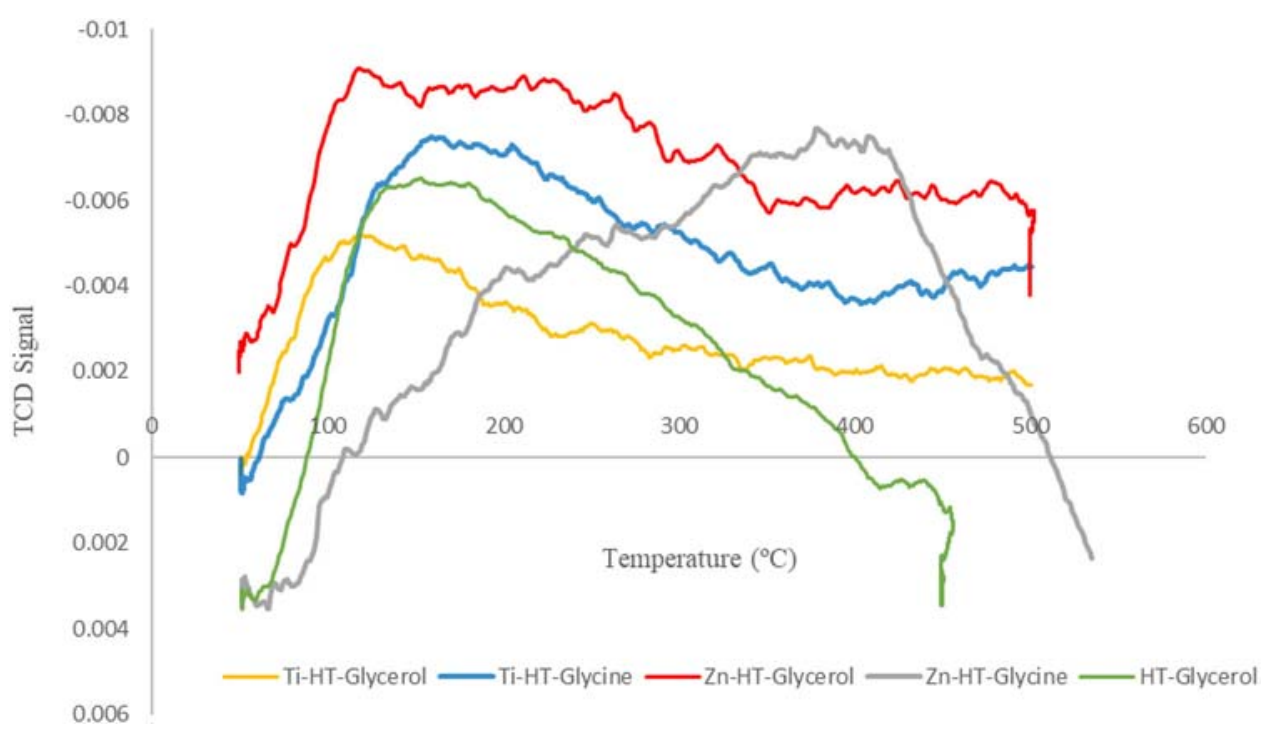

Figure 3. $\mathrm{CO}_{2}$-TPD thermograms for different catalysts.

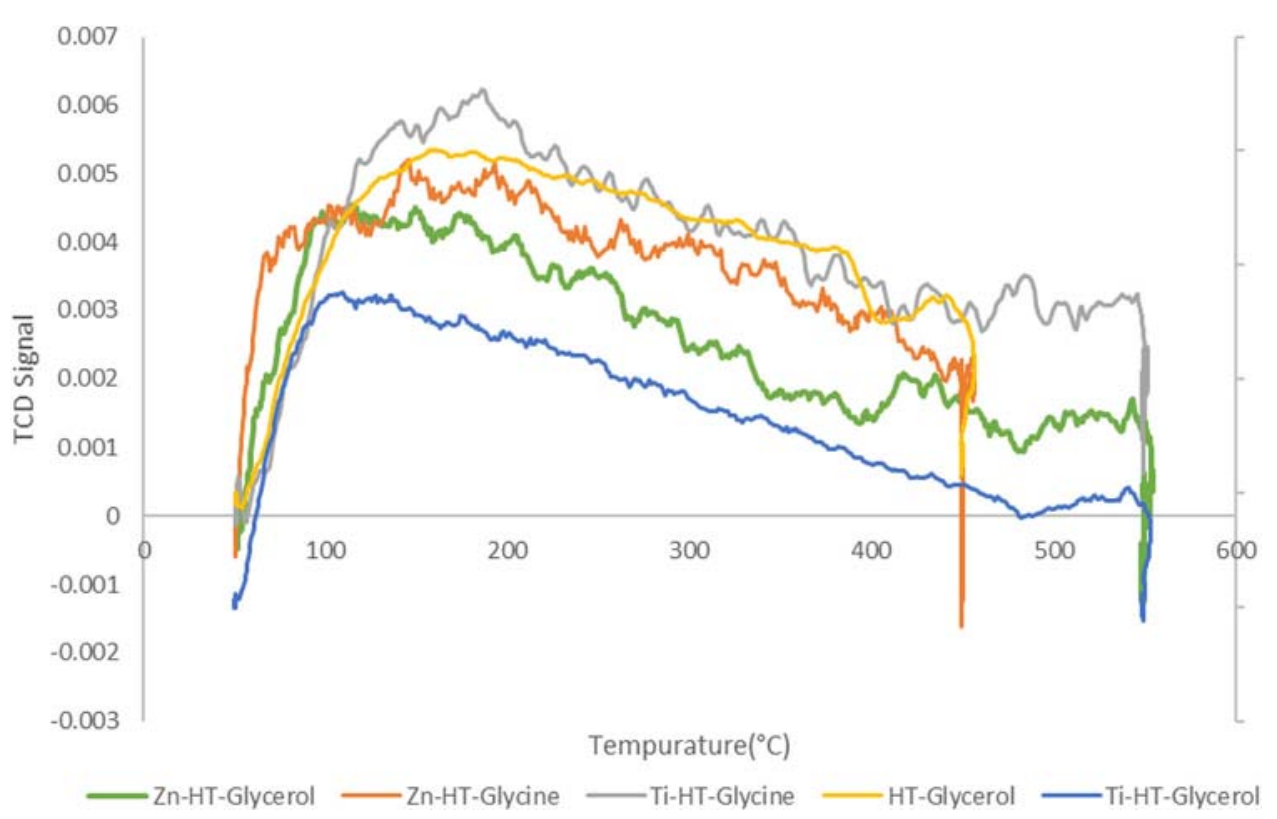

Figure 4. $\mathrm{NH}_{3}$-TPD thermograms for different catalysts.

due to the change in fuel from glycerol to glycine, acidity decreases and basicity increases which plays an important role in improving the activity of the catalyst.

3.1d Morphology properties by XRD: XRD is a beneficial technique to determine morphology, crystal size, purity and characteristics of any solid material. Figure 5 indicates the XRD pattern for $\mathrm{Ti}$ and Zn-HT with glycine and glycerol as fuels and HTGlycerol with $\mathrm{Al} / \mathrm{Mg}$ ratio of 1:2, 1:4 and 1:3, respectively. Incorporation of a tetravalent ion such as $\mathrm{Zr}^{4+}$ and $\mathrm{Ti}^{4+}$ in the structure, as a partial replacement of the $\mathrm{M}^{2+}$ or $\mathrm{M}^{3+}$ ions, was found to enhance the anion exchange capacity as well as alter the acido-basic properties of the resulting mixed oxides. ${ }^{36,37}$ It has been reported that $\mathrm{Zr}^{4+}$ containing hydrotalcites such as $\mathrm{Mg} / \mathrm{Al}, \mathrm{Zn} / \mathrm{Al}$ and also $\mathrm{Ni} / \mathrm{Al}$ compounds have excellent catalytic properties and used in important reactions. In the case of $\mathrm{Mg} / \mathrm{Al}, \mathrm{Al}^{3+}$ is isomorphously substituted by $\mathrm{Ti}^{4+}$ in the brucite layer ${ }^{37-39}$ which has been also reported earlier. Calcination at $650{ }^{\circ} \mathrm{C}$ leads to the collapse of crystalline $\mathrm{MgO}$ type of structure reducing the intensity of peaks. Besides original LDH could reconstitute upon rehydration at atmospheric pressure and room temperature. Our XRD analysis (Figure 5) BET (Table 3) and SEM images (Figure 1) confirmed this behavior. In Figure 5 reflections at different $2 \theta$ 


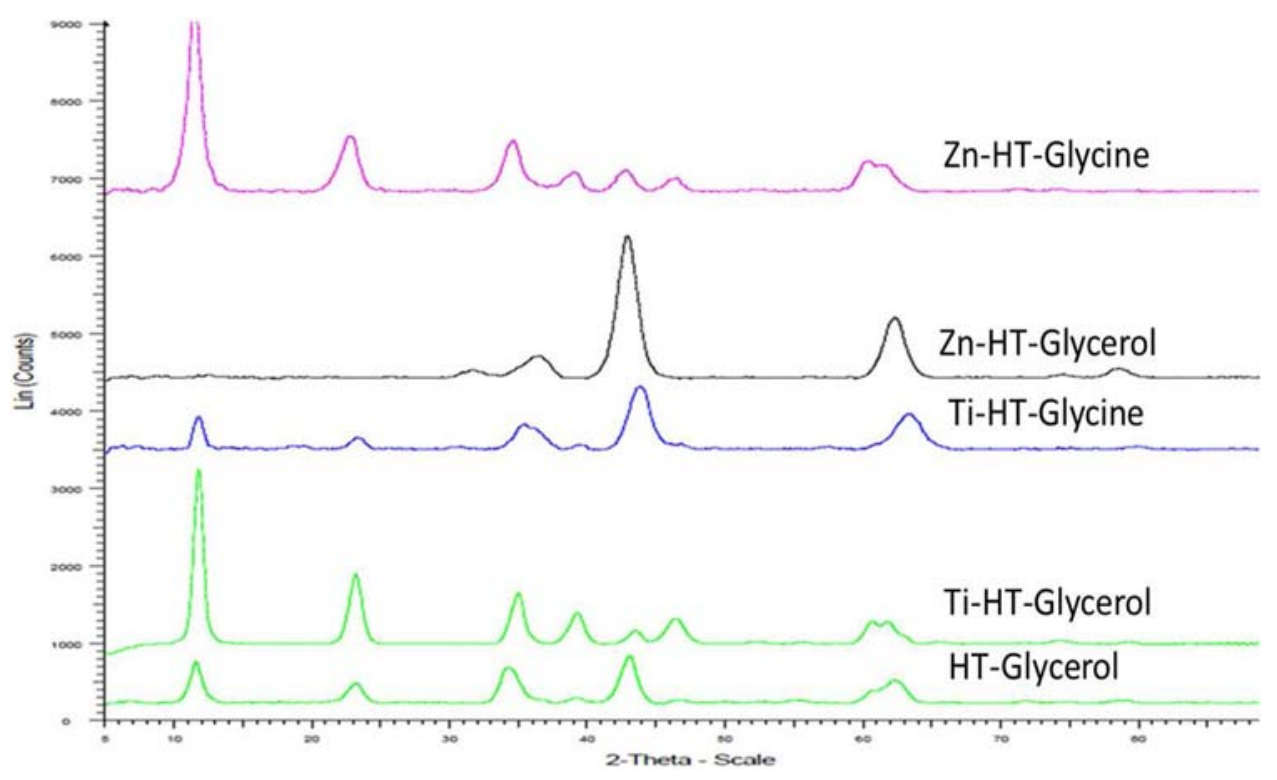

Figure 5. XRD patterns of Zn-HT, Ti-HT with Glycine and glycerol as fuels and HT-Glycerol.

Table 4. Analytical data by XRD for catalysts prepared by combustion method.

\begin{tabular}{lccc}
\hline Catalyst & $2 \theta^{\circ}$ & FWHM & Crystal size (nm) \\
\hline Ti-HT-Glycine & 43.88 & 1.804 & 4.98 \\
Ti-HT-Glycerol & 11.72 & 0.757 & 11.02 \\
Zn-HT-Glycine & 11.40 & 1.071 & 7.79 \\
Zn-HT-Glycerol & 34.28 & 1.32 & 6.58 \\
HT-Glycerol & 43.148 & 0.996 & 8.98 \\
\hline
\end{tabular}

values indicate different metals in the catalysts (ICDD card number matching). $\mathrm{Ti}$ and $\mathrm{Zn}-\mathrm{HT}$ with glycine and glycerol as fuels and HT-Glycerol reveal different reflections for different $2 \theta$ values showing that catalysts have layered FCC, FCC, BCC, hexagonal, crystalline structure, respectively. Nanocrystalline nature of all catalysts can be seen by the broadness of peaks. The crystal size of the sample was estimated by using Scherrer's formula which is in the range of 4-11 nm for all catalysts (Table 4). The most active catalyst Ti-HT-Glycine possesses the smallest crystal size of $4.98 \mathrm{~nm}$ providing more active sites for reaction. Mg-Al-Ti LDH has been prepared by co-precipitation with di-, tri- and tetra-valent cations, such as different $\mathrm{Al}^{3+} / \mathrm{Ti}^{4+}$ ratio, and used as active visible-light photocatalysts. ${ }^{38,39}$ It is found that no hydrotalcite structure was formed for $\mathrm{Ti}^{4+} /\left(\mathrm{Ti}^{4+}+\mathrm{Al}^{3+}\right)>0.5$ and the substitution of $\mathrm{Ti}^{+4}$ for $\mathrm{Al}^{3+}$ in the layer increases the thermal stability of the resulting LDH materials. ${ }^{36} \mathrm{In}$ our case the Ti-HT-Glycine with $\mathrm{Ti}^{4+} /\left(\mathrm{Ti}^{4+}+\mathrm{Al}^{3+}\right)=$ 0.494 has retained HT structure with increased thermal stability.

\subsection{Catalytic activity}

Scheme 1 shows the reaction of benzaldehyde with malononitrile to produce benzylidene malononitrile.

3.2a Reaction scheme and effect of solvent: Synthesis of benzylidene malononitrile by Knoevenagel condensation of benzaldehyde and malononitrile was carried out by using various solvents such as ethyl acetate, methanol and toluene but the conversion of benzaldehyde was less after $4 \mathrm{~h}$ in all the solvents and also it was hampering the selectivity of benzylidene malononitrile. The effect of solvent is very complex, and there are a number of factors that influence the rate of reaction and selectivity of the product. This is because of the competitive adsorption of the solvent molecule on the catalyst surface. It can be determined by the $\delta$ value, which states that solvents with negative $\delta$ value have the very least interaction with a metal catalyst, whereas the interaction of an organic solvent increases with a change in $\delta$ value from negative to positive. Here, we can see that the value of $\delta$ increases in the following order: ethyl acetate $<$ methanol $<$ toluene. Ethyl acetate with a lower value of $\delta$ gives maximum conversion, whereas toluene gives the least conversion. Literature also shows that in the synthesis of benzylidene malononitrile by Knoevenagel condensation of benzaldehyde and malononitrile, ethyl acetate is commonly used as solvent due to its less interaction with catalyst, high recovery, low vapor pressure, high conversion and selectivity. ${ }^{40}$

3.2b Efficacy of catalysts: The efficacy of the different modified catalysts was compared with HT-Glycerol. 


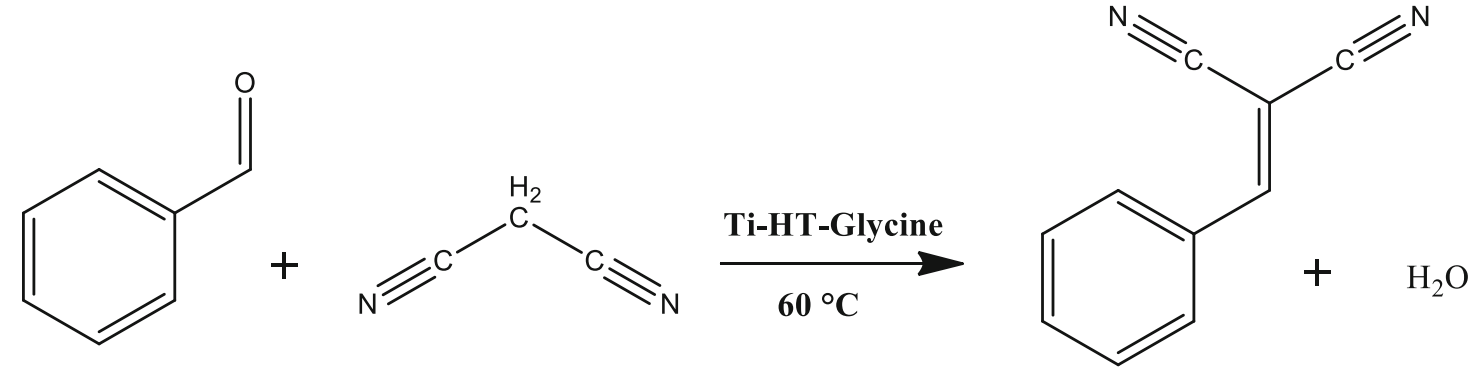

Benzaldehyde

Malononitrile

Benzylidene malononitrile

Scheme 1. Overall reaction for the production of benzylidene malononitrile

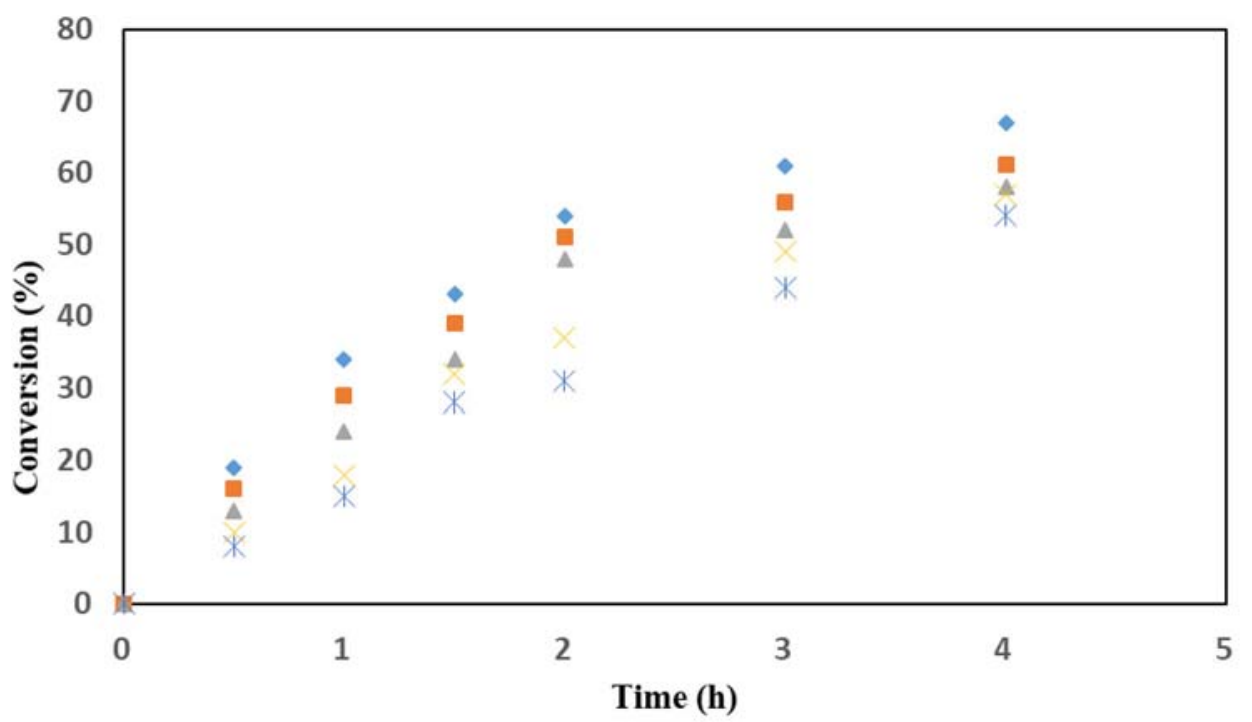

- Ti-HT-Glycine $=$ Ti-HT-Glycerol $\Delta$ Zn-HT-Glycine $\quad$ Zn-HT-Glycerol $×$ HT-Glycerol

Figure 6. Effect of different catalysts on conversion of benzaldehyde.

Figure 6 shows that the conversion of benzaldehyde is the highest $(66.9 \%)$ with Ti-HT-Glycine due to more active sites on its surface. It is due to bigger surface area, active sites and high basicity of Ti-HT-Glycine. The characterization data supported this result. The blank test was also conducted without the use of catalyst which gave only $4 \%$ conversion of benzaldehyde in $7 \mathrm{~h}$.

3.2c Effect of speed of agitation: The effect of speed of agitation was studied at $60{ }^{\circ} \mathrm{C}$ for a catalyst loading of $0.0025 \mathrm{~g} / \mathrm{cm}^{3}$ (Figure. 7). It was found that in the range of stirrer speed 1000-1200 rpm, there was no effect on the rates of reaction. Both selectivity and conversion remained almost constant after $1000 \mathrm{rpm}$ indicating the absence of mass transfer resistance. Selectivity to the product was $100 \%$. Hence, all further experiments were carried out at $1000 \mathrm{rpm}$. A theoretical analysis of the assessment of external mass transfer resistance, as given in some of our earlier work, confirmed that mass transfer resistance was negligible.

3.2d Effect of catalyst loading: The reaction rate is directly proportional to the loading of catalyst in the absence of external mass transfer resistance. The catalyst loading was changed from $0.0125-0.06 \mathrm{~g}$ corresponding to $6.25 \times 10^{-4}-3 \times 10^{-3} \mathrm{~g} / \mathrm{cm}^{3}$ on the basis of total reaction mixture volume (Figure 8 ). Benzaldehyde conversion increases as catalyst loading increases which owe to increase in the number of active sites in the same proportion. The selectivity was $100 \%$ in all cases. The initial rate of reaction increases with catalyst loading (Figure 9). However, from a catalyst loading range 0.05 to $0.06 \mathrm{~g}$ in the same total reaction mixture volume, there was no substantial increase in the final conversion and also selectivity of the product remained unaffected. It would mean the number of active sites available for reaction exceeds the number of moles of 


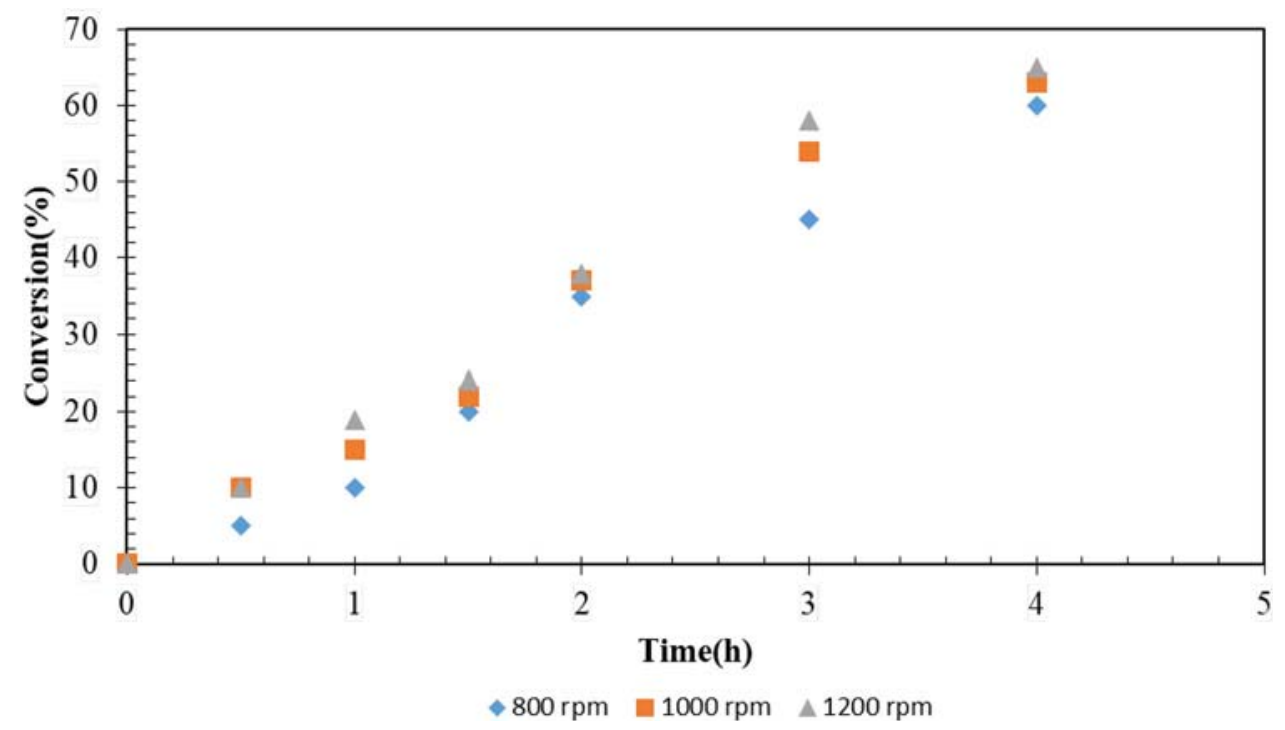

Figure 7. Effect of speed of agitation on conversion of benzaldehyde.

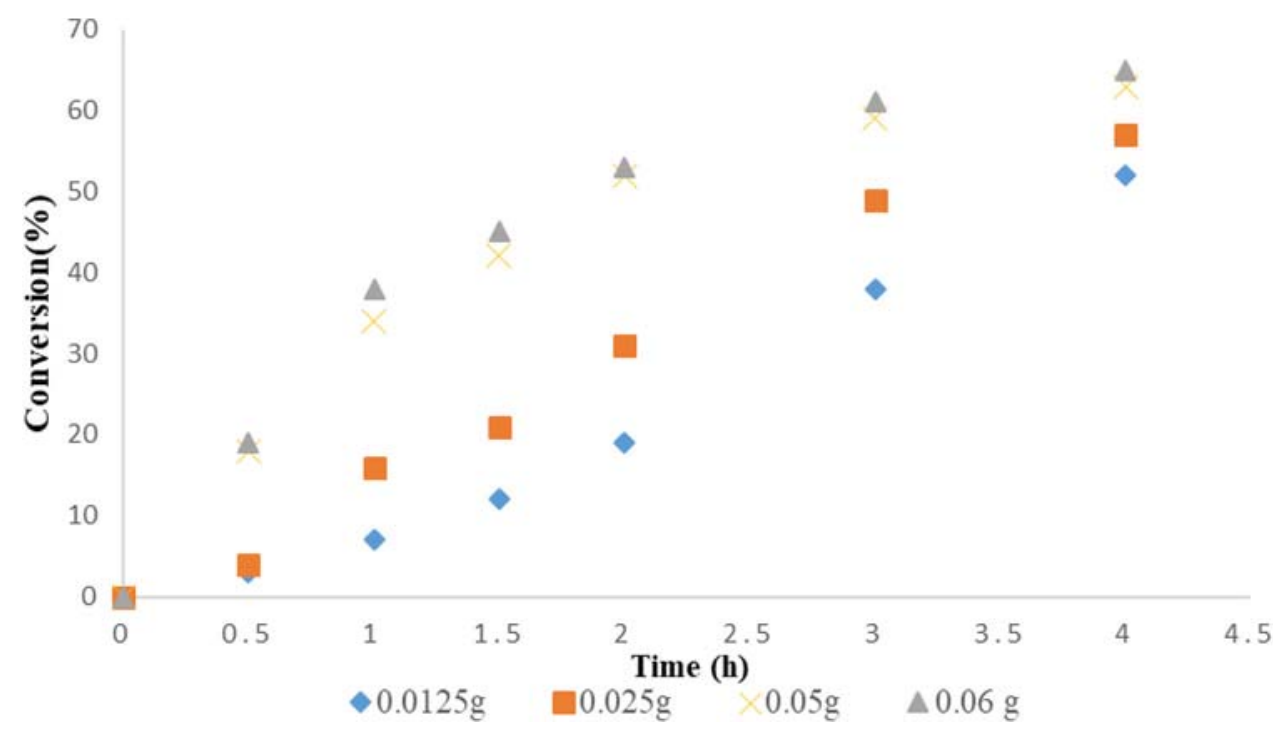

Figure 8. Effect of catalyst loading on conversion of benzaldehyde.

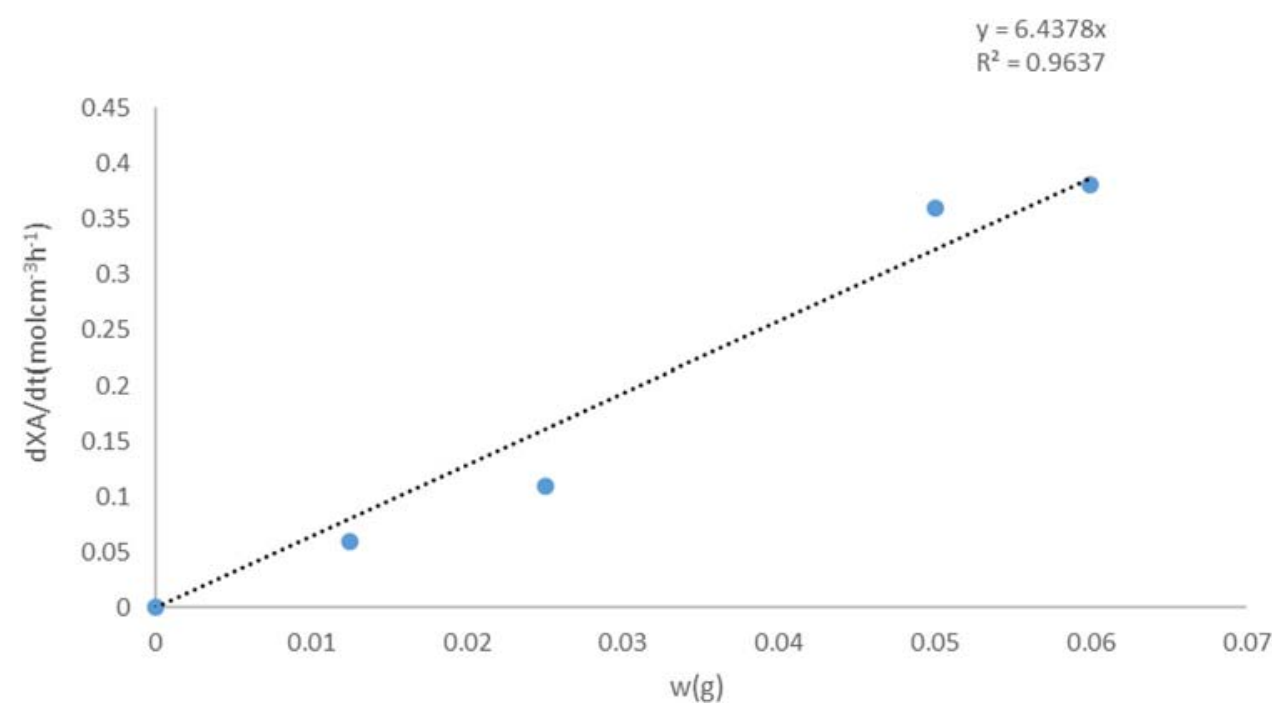

Figure 9. Plot of initial rate versus catalyst loading showing linear relationship. 


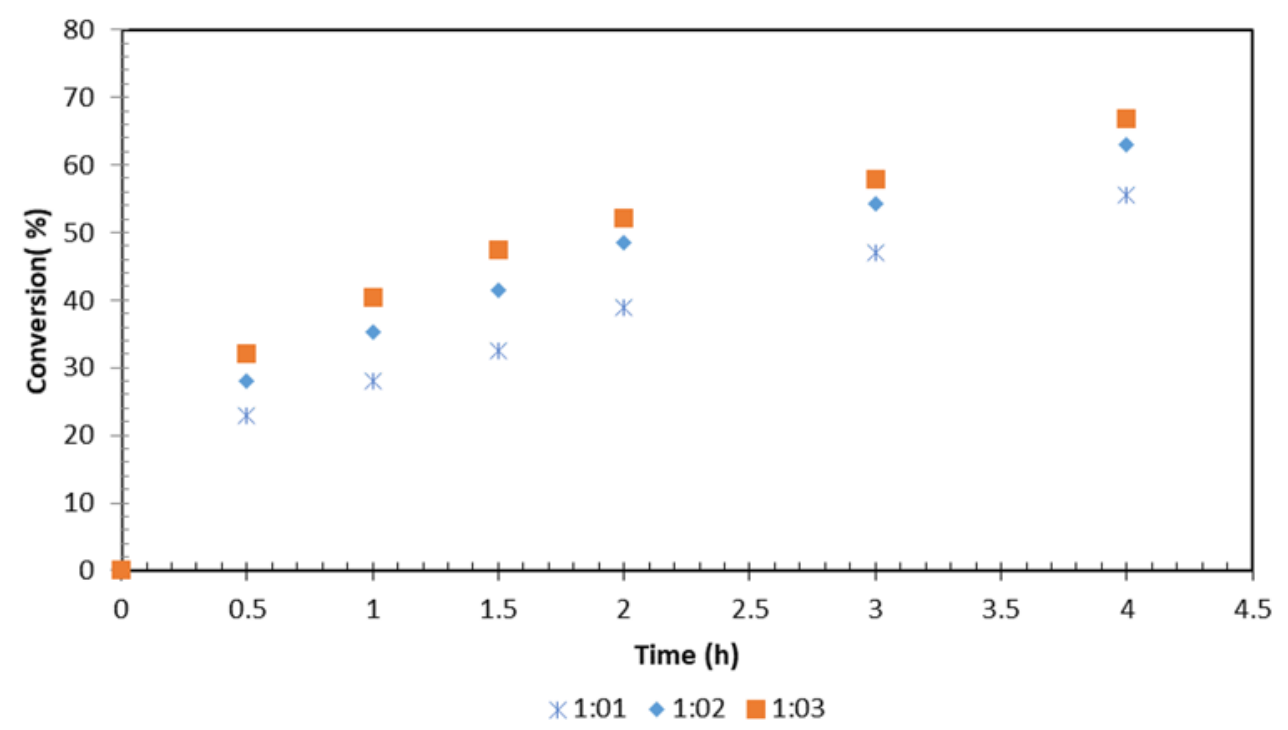

Figure 10. Effect of mole ratio of benzaldehyde to malononitrile on conversion of benzaldehyde.

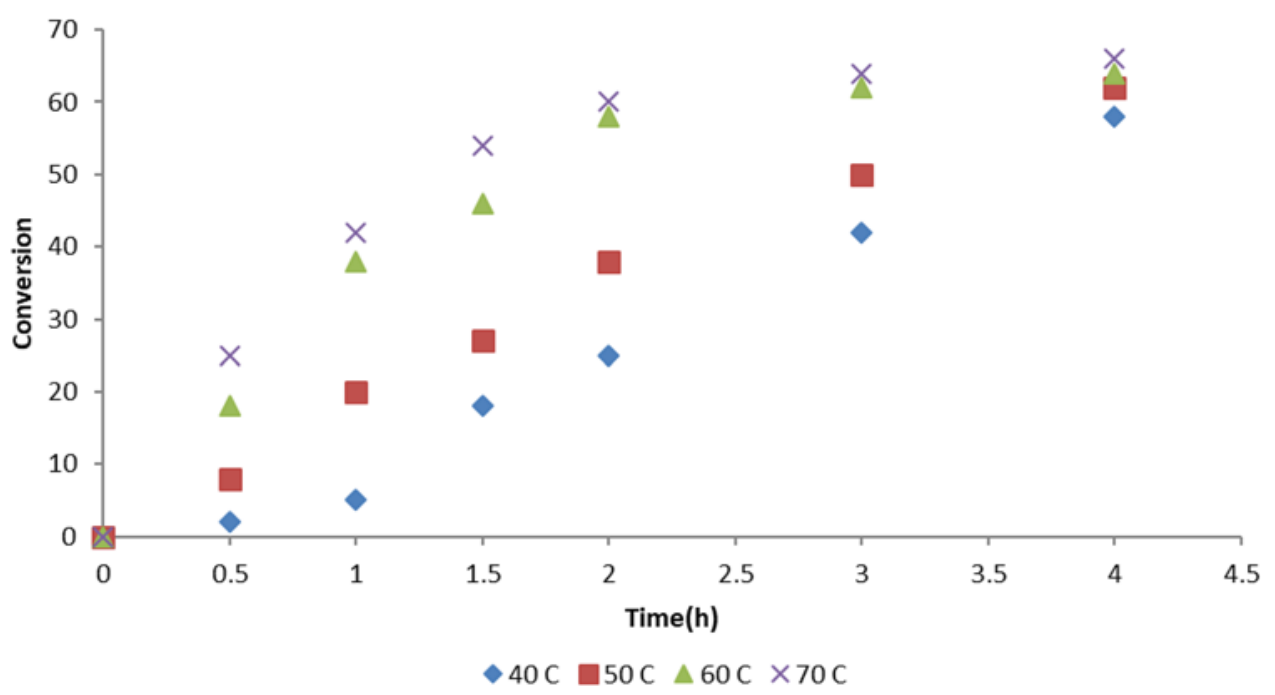

Figure 11. Effect of temperature on conversion of benzaldehyde.

reactants beyond $0.05 \mathrm{~g}$. All subsequent experiments were carried out using catalyst loading of $0.05 \mathrm{~g}$ which corresponded to $2.5 \times 10^{-3} \mathrm{~g} / \mathrm{cm}^{3}$ of the total volume of reaction.

3.2e Effect of mole ratio: During the reaction, the concentration of benzaldehyde and malononitrile was changed through the mole ratio of benzaldehyde and malononitrile in solvent ethyl acetate while keeping the liquid phase volume constant at $20 \mathrm{~mL}$. Benzaldehyde was taken as the limiting reactant and the amount of malononitrile varied from 1:01 (benzaldehyde 0.0094 mol, malononitrile $0.01408 \mathrm{~mol}$ ) to 1:03 (benzaldehyde $0.0094 \mathrm{~mol}$, malononitrile $0.0422 \mathrm{~mol}$ ). The overall reaction rate increased with increasing concentration of malononitrile (Figure 10). It indicates that the initial rate of reaction is proportional to the concentration of malononitrile.

3.2f Effect of temperature: The effect of temperature was studied from 40 to $70{ }^{\circ} \mathrm{C}$. The rate of reaction increased significantly with temperature and there was a substantial increase in the conversion which indicates that the reaction is controlled by the chemical kinetic step (Figure 11).

3.2g Reusability of catalyst: After completion of the reaction the catalyst was filtered off, refluxed with $10 \mathrm{~mL}$ ethyl acetate for $30 \mathrm{~min}$, separated and again refluxed with $15 \mathrm{~mL}$ ethyl acetate to remove any adsorbed reactants and products from the pore space and surface of the catalyst. Thereafter it was dried at $120^{\circ} \mathrm{C}$, calcined at 
Table 5. Reusability of Ti-HT-Glycine catalyst.

\begin{tabular}{|c|c|c|c|}
\hline Run No. & $\begin{array}{l}\text { Conversion of } \\
\text { benzaldehyde }\left(X_{A}\right) \%\end{array}$ & $\begin{array}{l}\text { Selectivity of } \\
\text { benzylidene } \\
\text { malononitrile }\left(S_{C}\right) \%\end{array}$ & $\begin{array}{l}\text { Yield of benzylidene } \\
\text { malononitrile }\left(S_{C}\right) \%\end{array}$ \\
\hline Fresh & 66.8 & 96.4 & 64.4 \\
\hline First use & 65.5 & 96.1 & 63.0 \\
\hline Second use & 63.9 & 95.5 & 61.0 \\
\hline
\end{tabular}

Table 6. Characterization of fresh and spent Ti-HT- Glycine catalyst.

\begin{tabular}{lcc}
\hline $\begin{array}{l}\text { Characterization } \\
\text { Parameter }\end{array}$ & $\begin{array}{c}\text { Fresh Ti-HT- } \\
\text { Glycine }\end{array}$ & $\begin{array}{c}\text { Spent Ti-HT- } \\
\text { Glycine }\end{array}$ \\
\hline Surface area $\left(\mathrm{m}^{2} / \mathrm{g}\right)$ & 226.2 & 210.6 \\
Pore volume $\left(\mathrm{cm}^{3} / \mathrm{g}\right)$ & 0.252 & 0.23 \\
Pore diameter $(\mathrm{nm})$ & 9.12 & 9.10 \\
Acidity $(\mathrm{mmol} / \mathrm{g})$ & 0.015 & 0.014 \\
Basicity $(\mathrm{mmol} / \mathrm{g})$ & 1.24 & 1.22 \\
\hline
\end{tabular}

$650^{\circ} \mathrm{C}$ for $3 \mathrm{~h}$ and cooled to room temperature. The catalyst was weighed to observe that there was a marginal loss which was made up by fresh catalyst for subsequent runs. The reusability study is given in Table 5. It is seen that catalyst activity and selectivity are maintained within experimental error. Comparative characterization of the fresh and spent catalyst after the second run is provided in Table 6 . There was an insignificant difference for pore volume and pore diameter whereas, a slight decrease in the surface area, acidity and basicity was observed between fresh and spent catalyst. Thus the catalyst was found to be stable and reusable.

3.2h Reaction mechanism: Since the catalyst is bifunctional having weak acidic $\left(\mathrm{S}_{1}\right)$ sites and strong basic $\left(S_{2}\right)$, a reaction mechanism was proposed as given in Scheme 2. In the proposed mechanism, the basic site $\left(\mathrm{S}_{2}\right)$ abstracts one proton from the active methylene group of malononitrile which is more acidic because of the presence of two strong electron-withdrawing nitrile (cyano) groups in the molecule. Thus, the conjugate base generated in situ is more stable as a result of conjugation with the two nitrile groups. ${ }^{41}$ This anion leads to a nucleophilic attack on to the carbonyl carbon atom of benzaldehyde attached on acidic site $\left(\mathrm{S}_{1}\right)$. The $\beta$-hydroxyl compound is generated when the negative charge over $\mathrm{O}$ picks up one proton from the catalyst and the catalyst is regenerated. The $\beta$-hydroxyl compound thus forms $\alpha, \beta$-unsaturated dicyano compound on basic site $\left(S_{2}\right)$ benzylidene malononitrile, through the elimination of one water molecule. It should be noted that the $\mathrm{C}$ atom attached with the nitrile group designated as $\alpha$ carbon.

3.2i Kinetic model: Based on the above mechanism a kinetic model was developed for Knoevenagel condensation reaction in the absence of both external mass transfer and intraparticle diffusion resistances. Preliminary data were interpreted using many models and the following was observed to fit the data well. As explained earlier chemisorption of A (benzaldehyde) and $\mathrm{B}$ (malononitrile) takes place on two nearby vacant sites $S_{1}$ and $S_{2}$,respectively, according to the LangmuirHinshelwood-Hougen-Watson (LHHW) mechanism to give $\mathrm{E}$ (benzylidene malononitrile, site $\mathrm{S}_{2}$ ) and $\mathrm{W}$ (water, site $\mathrm{S}_{1}$ ).

Adsorption of benzaldehyde A on vacant acidic site $\mathrm{S}_{1}$,

$A+S_{1} \stackrel{K_{A}}{\rightleftarrows} A S_{1}$

Similarly, on another vacant basic site $S_{2}$, malononitrile gets adsorbed as,

$B+S_{2} \stackrel{K_{B}}{\rightleftarrows} B S_{2}$

In $3^{\text {rd }}$ step adsorbed species react to give products $\mathrm{ES}_{2}$ and $\mathrm{WS}_{1}$ on active sites as follows,

$A S_{1}+B S_{2} \stackrel{K_{2}}{\rightleftarrows} E S_{2}+W S_{1}$

Finally, desorption of complexes formed $\mathrm{ES}_{2}$ and $\mathrm{WS}_{1}$ is represented by following reversible reactions

$E S_{2} \stackrel{1 / K_{E}}{\rightleftarrows} E+S_{2}$

$W S_{1} \stackrel{K_{W}}{\rightleftarrows} W+S_{1}$

giving regeneration of active sites $S_{1}$ and $S_{2}$ finally.

The derivation of the rate equation is given in Supplementary Information (SI).

If the surface reaction controls the reaction, then the reaction rate of $\mathrm{A}$ is given by a second order rate equation:

$-r_{A}=-\frac{d C_{A}}{d t}=k_{R_{2}} w C_{A} C_{B}$ 


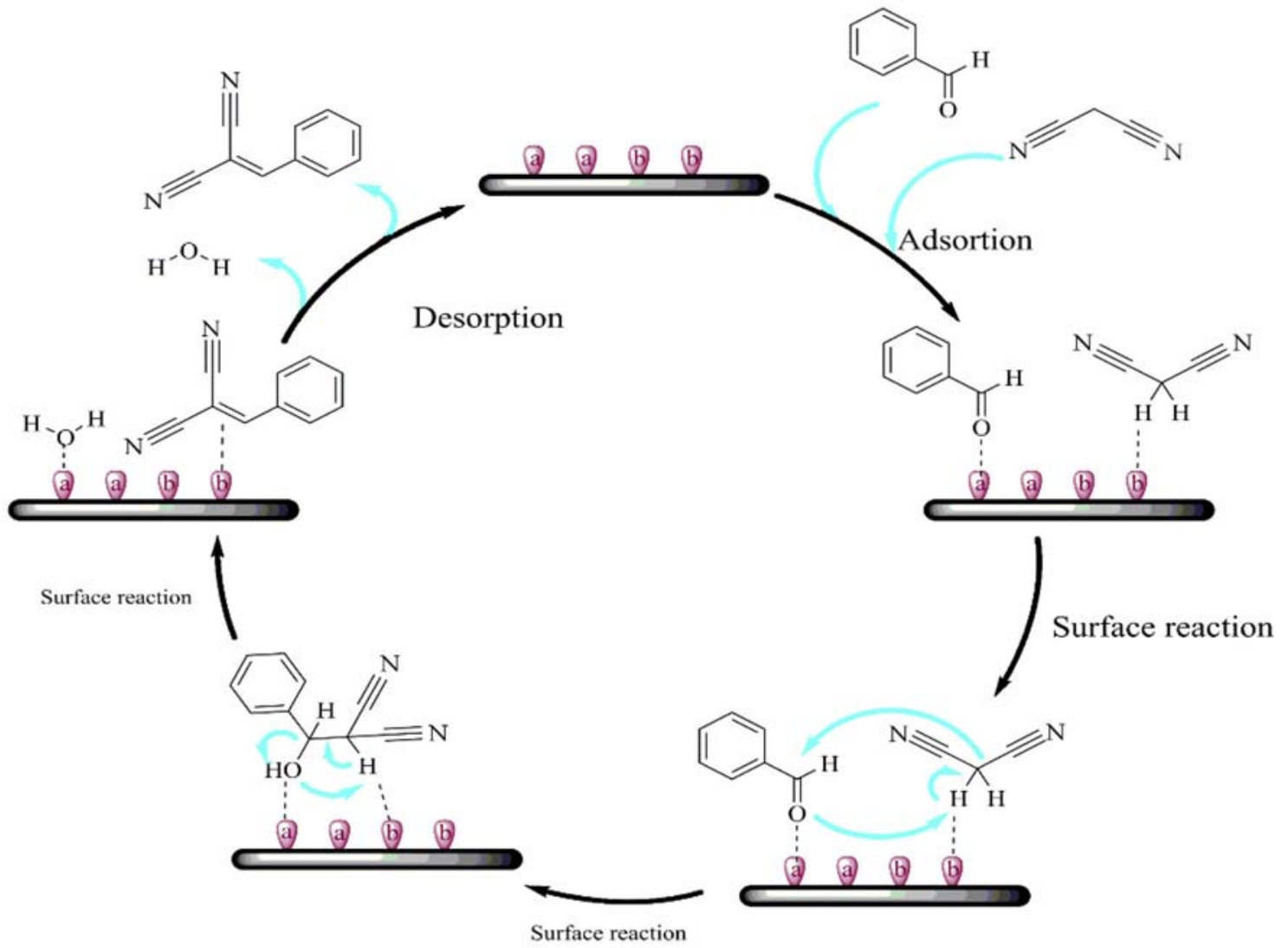

Scheme 2. Catalytic cycle for the Knoevenagel condensation over Ti-HT-Glycine ( $\mathrm{a}$ - acid site, $\mathrm{b}$ - base site).

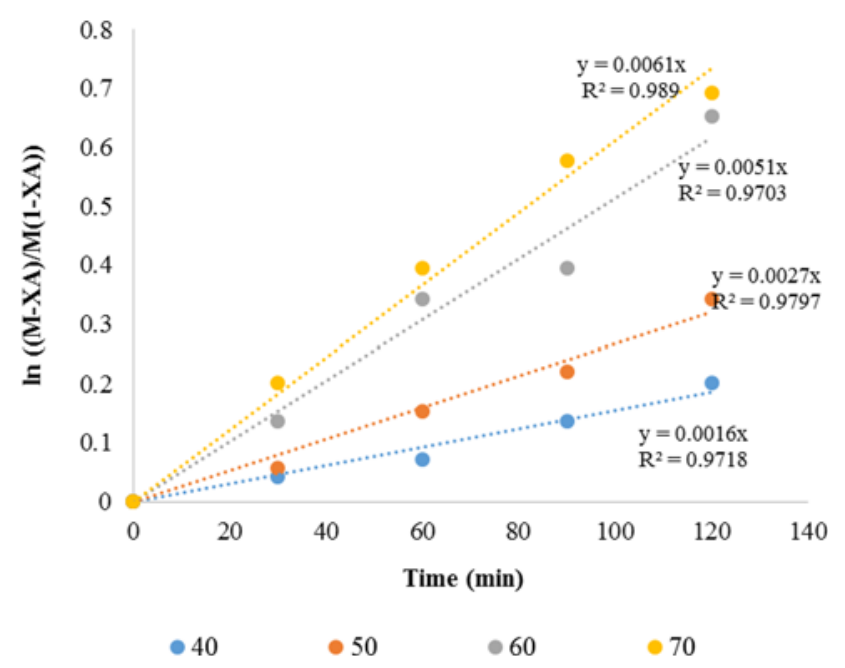

Figure 12. Validity of model: Kinetic plots for various temperatures.

Which on integration gives the following:

$\ln \left[\frac{\left(M-X_{A}\right)}{M\left(1-X_{A}\right)}\right]=k_{R_{2}} C_{A_{0}} w t=k t$

Where $X_{A}$ is fractional conversion of $\mathrm{A}$ and $M=\frac{C_{B_{0}}}{C_{A_{0}}}$, initial mole ratio of concentration of $\mathrm{B}$ to $\mathrm{A}$

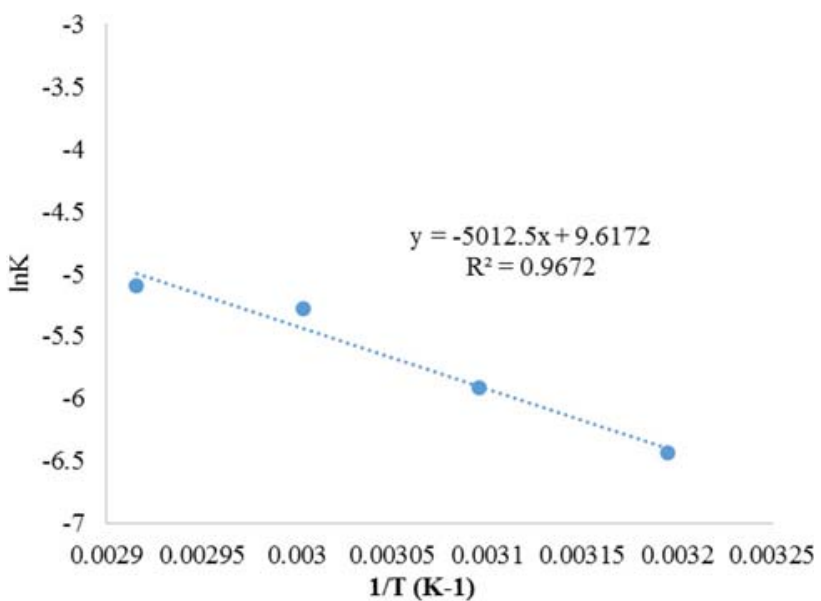

Figure 13. Arrhenius plot.
A plot of $\ln \left[\frac{\left(M-X_{A}\right)}{M\left(1-X_{A}\right)}\right]$ versus time was made for different temperatures which are straight lines passing through origin which confirms that the reaction is second order and validates the kinetic model (Figure 12). The slopes of these lines $k$ were used to make the Arrhenius plot (Figure 13). The apparent activation energy was found to be $10.01 \mathrm{kcal} / \mathrm{mol}$ which confirmed that 
the reaction rate was controlled by intrinsic kinetics at the catalyst surface.

\section{Conclusions}

Al-Mg hydrotalcite (HT) was modified with Ti and Zn using glycine and glycerol as two different fuels in the combustion synthesis method. This is the first report which contains synthesis, full characterization and comparison of heterogeneous Ti-HT and Zn-HT with glycine and glycerol as fuels. All five catalysts including HT-Glycerol were evaluated in the Knoevenagel condensation between benzaldehyde and malononitrile to give benzylidene malononitrile as the product. Among these, Ti-HT-Glycine was the most active and selective in comparison with other reported catalysts. The study also shows that fuel plays an important role in determining the performance of the catalyst in the combustion method. It gave $67 \%$ conversion of benzaldehyde in 4 $\mathrm{h}$ at $60{ }^{\circ} \mathrm{C}$ with mole ratio 1:03 of benzaldehyde and malononitrile with a catalyst loading of $0.0025 \mathrm{~g} / \mathrm{cm}^{3}$. LHHW model was fitted with weak adsorption of all species leading to second-order kinetics with apparent energy of activation $10.01 \mathrm{kcal} / \mathrm{mol}$. The catalyst could be used thrice without loss of activity. Ti-HT-Glycine can be used for different base catalyzed industrial important heterogeneous reactions.

\section{Supplementary Information (SI)}

Supplementary information for this article is available at www.ias.ac.in/chemsci.

\section{Acknowledgements}

ALJ thanks the management of D.Y. Patil College of Engineering and Technology, Kolhapur for permitting him to do this doctoral work. Thanks are also due to Dr. Godfree Fernandes for his help. GDY acknowledges support from R.T. Mody Distinguished Professor Endowment, Tata Chemicals Darbari Seth Distinguished Professor of Leadership and Innovation, and J. C. Bose National Fellowship of Department of Science and Technology, GoI.

\section{Compliance with ethical standards}

Conflict of interest The authors declare that they have no conflict of interest.

\section{References}

1. Lopez T, Bosch P, Ramos E, Gomez R, Novaro O, Acosta D and Figueras F 1996 Synthesis and characterization of sol-gel hydrotalcites. Structure and texture Langmuir 12189
2. Cavani F and Trifiro A 1991 Hydrotalcite-type anionic clays: Preparation, properties and applications Catal. Today 11173

3. Hattori H 1995 Heterogeneous basic catalysis Chem. Rev. 95537

4. Cosimo J, Di I, Díez V K, Xu M, Iglesia E and Apesteguía C R 1998 Structure and surface and catalytic properties of Mg-Al basic oxides J. Catal. 178499

5. Ono Y 2003 Solid base catalysts for the synthesis of fine chemicals J. Catal. 216406

6. Gupta M, Gupta R and Anand M 2009 Hydroxyapatite supported caesium carbonate as a new recyclable solid base catalyst for the Knoevenagel condensation in water Beilstein J. Org. Chem. 51

7. Delsarte S, Maugé F, Lavalley J C and Grange P 2000 Basic sites on mixed nitrided galloaluminophosphates "AlGaPON": Infrared studies of $\mathrm{SO}_{2}$ and $\mathrm{CDCl}_{3}$ adsorption Catal. Lett. 6879

8. Sakthivel B and Dhakshinamoorthy A 2017 Chitosan as a reusable solid base catalyst for Knoevenagel condensation reaction J. Colloid Interface Sci. 48575

9. Climent M J, Corma A, Iborra S and Primo J 1995 Base catalysis for fine chemicals production: Claisen-Schmidt condensation on zeolites and hydrotalcites for the production of chalcones and flavanones of pharmaceutical interest J. Catal. 15160

10. Yadav G D and Yadav A R 2014 Novelty of ClaisenSchmidt condensation of biomass-derived furfural with acetophenone over solid super base catalyst RSC Adv. 4 63772

11. Meyer U and Gorzawski H 1999 Michael addition of ethyl acrylate and acetone over solid bases Catal. Letters $\mathbf{5 9} 201$

12. Yadav G D and Kadam A A 2013 Selective engineering using $\mathrm{Mg}-\mathrm{Al}$ calcined hydrotalcite and microwave irradiation in mono-transesterification of diethyl malonate with cyclohexanol Chem. Eng. J. 230547

13. Climent M J, Corma A, Fornés V, Guil-Lopez R and Iborra S 2002 Aldol condensations on solid catalysts: A cooperative effect between weak acid and base sites $A d v$. Synth. Catal. 3441090

14. Yadav G D and Aduri P 2012 Aldol condensation of benzaldehyde with heptanal to jasminaldehyde over novel $\mathrm{Mg}-\mathrm{Al}$ mixed oxide on hexagonal mesoporous silica $J$. Mol. Catal. A Chem. 355142

15. Delidovich I and Palkovits R 2015 Structureperformance correlations of $\mathrm{Mg}-\mathrm{Al}$ hydrotalcite catalysts for the isomerization of glucose into fructose $J$. Catal. 3271

16. King F and Kelly G J 2002 Combined solid base/hydrogenation catalysts for industrial condensation reactions Catal. Today $\mathbf{7 3} 75$

17. Patankar S K, Dodiya S and Yadav G D 2015 Cascade engineered synthesis of ethyl benzyl acetoacetate and methyl isobutyl ketone (MIBK) on novel multifunctional catalyst J. Mol. Catal. A: Chem. 409171

18. Shukla K and Srivastava V 2017 Synthesis of organic carbonates from alcoholysis of urea: A review Catal. Rev. 591

19. Yadav G D and Chandan P A 2014 A green process for glycerol valorization to glycerol carbonate over heterogeneous hydrotalcite catalyst Catal. Today 23747 
20. Kondawar S and Rode C V 2017 Solvent-free glycerol transesterification with propylene carbonate to glycerol carbonate over a solid base catalyst Energy Fuels 314361

21. Yadav G D and Fernandes G P 2013 Selective synthesis of natural benzaldehyde by hydrolysis of cinnamaldehyde using novel hydrotalcite catalyst Catal. Today 207 162

22. Fernandes G P and Yadav G D 2018 Selective glycerolysis of urea to glycerol carbonate using combustion synthesized magnesium oxide as catalyst Catal. Today $\mathbf{3 0 9}$ 153

23. Jyothi T M, Raja T, Talawar M B and Rao B S 2001 Selective $O$-methylation of catechol using dimethyl carbonate over calcined $\mathrm{Mg}$-Al hydrotalcites Appl. Catal. A Gen. 21141

24. Yadav G D and Salunke J Y 2013 Selectivty engineering of solid base catalyzed $O$-methylation of 2 napthol with dimethyl carbonate to 2-methoxy napthalene Catal. Today 207180

25. Yadav G D and Surve P S 2013 Solventless green synthesis of 4-O-aryloxy carbonates from aryl/alkyloxy propanediols and dimethyl carbonate over nanocrystalline alkali promoted alkaline earth metal oxides Catal. Sci. Technol. 32668

26. Bhanawase S L and Yadav G D 2017 Hydrotalcite as active and selective catalyst for synthesis of dehydrozingerone from vanillin and acetone: Effect of catalyst composition and calcination temperature on activity and selectivity Curr. Catal. 6105

27. Bhanawase S L and Yadav G D 2017 Activity and selectivity of different base catalysts in synthesis of guaifenesin from guaiacol and glycidol of biomass origin Catal. Today 291213

28. Bhanawase S L and Yadav G D 2016 Green synthesis of vanillyl mandelic acid (sodium salt) from guaiacol and sodium glyoxylate over novel silica encapsulated magnesium hydroxide ACS Sustain. Chem. Eng. 41974

29. Bhanawase S L and Yadav G D 2017 Novel alkalipromoted hydrotalcite for selective synthesis of 2methoxy phenyl benzoate from guaiacol and benzoic anhydride Clean Technol. Environ. Policy 191169
30. Molleti J and Yadav G D 2017 Green synthesis of veratraldehyde using potassium promoted lanthanummagnesium mixed oxide catalyst Org. Process Res. Dev. 211012

31. Deshmukh G P and Yadav G D 2017 Facile synthesis of dicamba ester over heterogeneous magnesium oxide and kinetic modelling Chem. Eng. J. 309663

32. Rao C N R 1994 Chemical Approaches to the Synthesis of Inorganic Materials (New Delhi: Wiley Eastern Limited)

33. Patil K 1997 Combustion synthesis Curr. Opin. Solid State Mater. Sci. 2158

34. Misono M 2013 Heterogeneous Catalysis of Mixed Oxides (Oxford: Elsevier B.V.)

35. Patil K C, Aruna S T and Mimani T 2002 Combustion synthesis: An update Curr. Opin. Solid State Mater. Sci. 6 507

36. Velu S, Ramaswamy V and Sivasanker S 1997 New hydrotalcite-like anionic clays containing $\mathrm{Zr}^{4+}$ in the layers Chem. Commun. 212107

37. Das N and Samal A 2004 Synthesis, characterisation and rehydration behaviour of titanium(IV) containing hydrotalcite like compounds Micropor. Mesopor. Mater. 72 219

38. Xia S J, Liu F X, Ni Z M, Shi W, Xue J L and Qian P P 2014 Ti-based layered double hydroxides: Efficient photocatalysts for azo dyes degradation under visible light Appl. Catal. B Environ. 144570

39. Hosni K, Abdelkarim O, Frini-Srasra N and Srasra E 2014 Synthesis, structure and photocatalytic activity of calcined Mg-Al-Ti-layered double hydroxides Korean J. Chem. Eng. 32104

40. Gawade A B, Tiwari, M S and Yadav G D 2016 Biobased green process: Selective hydrogenation of 5hydroxymethylfurfural to 2,5-dimethyl furan under mild conditions using Pd- $\mathrm{Cs}_{2.5} \mathrm{H}_{0.5} \mathrm{PW}_{12} \mathrm{O}_{4} 0 / \mathrm{K}-10$ Clay ACS Sustain. Chem. Eng. 44113

41. Mondal J, Modak A and Bhaumik A 2011 Highly efficient mesoporous base catalyzed Knoevenagel condensation of different aromatic aldehydes with malononitrile and subsequent noncatalytic Diels-Alder reactions $J$. Mol. Catal. A-Chem. 335236 